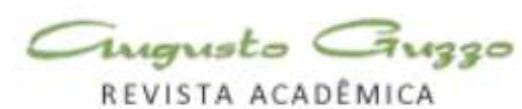

\title{
Contratos Internacionais E Cláusulas Hardship
}

\author{
International Contracts And Clauses Hardship
}

\author{
Carolina Gladyer Rabelo
}

\begin{abstract}
Doutoranda em Direito Econômico na Pontifícia Universidade Católica de São Paulo - PUC-SP. Possui Mestrado em Direito Internacional pela Universidade Católica de Santos - UNISANTOS (2009) e Graduação em Direito pela Universidade Católica de Santos (2006). Advogada Inscrita na Ordem dos Advogados do Brasil Seccional São Paulo desde 2007, atuando precipuamente no âmbito consultivo financeiro, tanto nacional quanto internacional. Gerente Jurídica da Associação Brasileira de Bancos - ABBC. Além de Advogada é Professora em cursos de Graduação e Pós-Graduação em São Paulo - SP. E-mail: cgrabelo@gmail.com
\end{abstract}

\section{Resumo}

A mudança de paradigma econômico vivenciada pela sociedade internacional no século XXI, derivada tanto da intensificação do processo de globalização, quanto do desenvolvimento tecnológico, além da maior aderência dos Estados ao princípio da autonomia da vontade e aos vários métodos de uniformização do Direito Internacional Privado, fez com que as formas de contratar fossem revisitadas. Do mencionado processo de globalização, depreendeu-se valorosa expansão comercial, que tornou necessário o estudo mais detido de um dos principais meios utilizados pelos Estados para participar dessa nova conjuntura econômica: os contratos internacionais do comércio. A efetivação das transações comerciais passa por um incomensurável número de obstáculos, tais como as diferenças entre os sistemas jurídicos contratantes e os arcabouços econômicos nacionais. Isso, sem contar os problemas básicos voltados à diversidade de língua e distância entre os contratantes. Todo esse contexto torna árdua a tarefa de concluir uma negociação internacional e, por conta desses fatores, sérios riscos de violação de direitos são percebidos. Nesse sentido, questiona-se: quem responde pelos riscos de um contrato internacional? Como devem ser analisadas as perdas? As constantes mutações da realidade internacional, a suscetibilidade dos contratos internacionais a tais transformações e a usual extensa duração de tais contratos, geram uma atmosfera de incertezas e evidente preocupação com os obstáculos que possam surgir e criar dificuldades na execução de um dado contrato, cuja complexidade pode aumentar radicalmente em face do conflito de leis entre as partes contratantes. Assim, no presente trabalho serão analisados os princípios norteadores dos contratos internacionais, bem como a "Cláusula Hardship", que permite a revisão do contrato, quando fundada na onerosidade excessiva, já que a intenção desta é possibilitar às partes a efetiva execução da obrigação e a manutenção do equilíbrio contratual, mesmo quando o contrato se prolongar por extenso período de tempo.

Palavras-chave: Direito Internacional, Contratos Internacionais, Cláusula Hardship, Onerosidade. 


\begin{abstract}
The shift in economic paradigm experienced by international society in the twenty-first century, derived both from the intensification of the globalization process, as technological development, as well as greater adherence of States to the principle of freedom of choice and the various methods of standardization of private international law, made forms of hiring were revisited. Mentioned the globalization process, valuable commercial expansion was surmised, requesting a careful study of one of the main means used by states to participate in this new economic environment: international trade agreements. The effectiveness of business transactions involves an immeasurable number of obstacles such as differences between the contractors' legal systems and national economic frameworks. Not to mention the basic problems facing the diversity of language and distance between the contractors. This context makes arduous the task of concluding an international trading and because of these factors serious risk of rights violations are perceived. In this sense, the questions are: who is liable for the risks of an international agreement? How losses can be analyzed? The constant changes of the international scenario, the sensitivity of international contracts to such changes and extensive usual duration of such contracts, generate an atmosphere of uncertainty and apparent concern about the obstacles that may arise and create difficulties in implementing a given contract, whose complexity can dramatically increase in the face of conflict of laws between the Parties. In the present work, the guiding principles will be reviewed in international contracts, as well as the "clause Hardship", which allows contract review, when founded in excessive burden, since the intent is to enable the parties to the effective implementation of the obligation and the maintenance of the contractual balance, even when the contract is prolonged for an extended period of time.
\end{abstract}

Keywords: International Law - International Contracts - Hardship Clause - Onerosity. 


\section{Introdução}

As realidades concorrenciais estão cada vez mais intensas. As exigências de consumo mais complexas e a consequente interligação entre empresas de vários países, em busca de um número maior de mercado consumidor, são patentes. Diante desta realidade mundial, o comércio internacional restou fortalecido, e por consequência, uma nova estrutura jurídica se fez necessária, visando o atendimento da exacerbada demanda de negócios entre empresas situadas em diferentes Estados.

Apesar da interação transnacional entre os Estados - proporcionada pelos meios de comunicação, a partir do movimento da globalização -, o desenvolvimento do comércio internacional trouxe consigo uma grande polêmica acerca do cumprimento das negociações comerciais travadas entre diferentes países, em função dos regimentos jurídicos de cada um. Por vezes, os contratos acabam gerando conflito entre as leis locais que regem cada uma das partes contratantes, criando dificuldades para os contratantes no momento de escolha da legislação aplicável.

E é neste embate que floresce o direito do comércio internacional, que tem como maior princípio regente o da Autonomia da Vontade, e, como objetivo primordial, a organização das relações contratuais no âmbito internacional. Uma das técnicas utilizadas para alcançar o objetivo da organização das relações contratuais e o cumprimento destas, foi a aplicação das cláusulas revisionais e exoneratórias de responsabilidade, que possibilitam às partes contratantes reavaliar as obrigações contraídas e suas condições de execução, na ocorrência de fatos que modifiquem substancialmente as circunstâncias iniciais do contrato, alterando o seu equilíbrio, de forma que o cumprimento se torne impossível ou extremamente oneroso.

O presente estudo tem como objeto uma dessas cláusulas: a hardship, que compreende uma cláusula revisional fundada na onerosidade excessiva. A cláusula de hardship é permeada de controvérsias, que se iniciam em sua égide, prolongam-se na sua relação com o secular princípio do pacta sunt servanda e recaem na sua estruturação prática contratual, o que torna seu estudo incontestavelmente importante e complexo.

Desta forma, a métrica escolhida para o presente trabalho, seguirá, primeiramente, no sentido do desenvolvimento de um breve estudo dos principais princípios formadores do contrato internacional, seguido da análise de sua conformação com a Teoria da Imprevisão e da cláusula rebus sic stantibus, ambas precursoras das cláusulas exoneratórias de responsabilidade.

Em seguida, serão apresentados os elementos formadores da cláusula de hardship e sua 
relação com outras cláusulas e princípios também aplicáveis aos contratos internacionais, tais como a cláusula de Força Maior e o princípio pacta sunt servanda, a fim de que se possa perceber a maneira como a conservação do equilíbrio dos contratos internacionais pode ser buscada.

\section{Natureza Jurídica Dos Contratos}

Negócio Jurídico, bilateral ou plurilateral, gerador de obrigações, que sujeita as partes à observância de conduta idônea à satisfação dos interesses que regularam. Orlando Gomes ${ }^{1}$ in 'Contratos', afirma que um contrato é o encontro de duas declarações convergentes de vontades, emitidas no propósito de constituir, regular ou extinguir, entre os declarantes, uma relação jurídica patrimonial de conveniência mútua.

O contrato traz em si a estrutura de um negócio jurídico, compreendendo suas diversas fases formativas e a finalização definida como a execução de seu objeto, trazendo igualmente a declaração de vontade das partes que o integram, além do cumprimento de uma prestação.

Para Irineu Strenger ${ }^{2}$, o único acréscimo à definição acima aduzida, voltando-se aos contratos internacionais, diz respeito ao âmbito da aplicação das leis. Nada além. Entretanto, os contratos internacionais integram a parte especial

\footnotetext{
${ }^{1}$ Rio de Janeiro: Forense, 1995, p.9.
}

do Direito Internacional Privado, e nesse campo, em especial, apresenta-se o princípio da autonomia da vontade como um dos tópicos mais importantes relacionados à determinação do direito aplicável. Segundo este princípio, as partes podem negociar e estabelecer cláusulas de acordo com suas necessidades e interesses, o que remete ao princípio do pacta sunt servanda, outrora suscitado. Para o ramo privado do Direito Internacional, a autonomia da vontade tem distinta característica do direito privado comum: as partes podem, no exercício de tal liberdade, determinar a escolha da lei aplicável aos contratos internacionais, da forma que melhor convier a todas. Esse princípio é aceito de forma pacífica pelos ordenamentos jurídicos estrangeiros e também é recepcionado pelos tribunais arbitrais.

\subsection{Contratos Internacionais}

Para fazer face ao consumo em massa, fruto do modelo capitalista hodierno, ocorre a necessidade do surgimento de um direito mercantil com especialidade técnica voltada à adequada sistematização das operações de circulação de bens e serviços no mercado internacional.

Ao comparar os contratos internos e os internacionais, além dos elementos inerentes àqueles, os internacionais envolvem interesses cuja

2 Contratos Internacionais do Comércio. São Paulo: Revista dos Tribunais, 1986, p.60.

\section{RABELO, C.G.: Contratos Internacionais E Cláusulas Hardship}


complexidade pode ser medida por vários elementos complicadores, dentre os quais podemos citar: a escolha da lei aplicável, a existência de sistemas jurídicos diferentes, o idioma e costumes diversos. Todavia, apesar de toda particularidade deste tipo contratual, não há nas regras jurídicas e nas decisões jurisprudenciais, uma única e uniforme definição de contrato internacional. Assim, a identificação de traços básicos que façam com que um contrato seja considerado como tal devem ser buscadas e, em linhas gerais, tal tipo contratual desenvolve o intercâmbio de mercadorias, serviços e capitais, entre empresas pertencentes a diferentes Estados.

\subsection{Dificuldades na Elaboração de}

\section{Contratos Internacionais}

\begin{abstract}
Dentre as principais dificuldades identificadas, pode-se comentar as barreiras burocráticas impostas aos produtos sujeitos ao comércio internacional. A demora excessiva na tramitação dos processos administrativos, os entraves nos processos de exportação e importação, o controle de fronteiras, a falta de informação das autoridades responsáveis, a ausência de regras claras relacionadas ao assunto e a limitação na divulgação dos procedimentos, perfazem o rol de itens que dificultam as trocas internacionais. Cabe também mencionar a questão do ônus ligado à origem tributária nos países exportadores e importadores, bem como, os
\end{abstract}

valores impostos à título de barreiras tarifárias e alfandegárias. Além disso, a existência de uma legislação protecionista ou até mesmo a inexistência de legislação específica ou clara sobre a matéria, também são grandes imbróglios verificados, tanto quanto as questões de ordem política, que constituem fortes impedimentos ao desenvolvimento e segurança das relações comerciais internacionais.

A natureza técnica também deve ser ressaltada como um real e potencial problema. Inúmeras vezes, quando um certo Estado quer dificultar a entrada de dado produto ou obstaculizar trocas comerciais com determinado país, exigências de certificação do produto e de sua origem por autoridades do país estrangeiro são solicitadas. Estas nem sempre são fáceis de conseguir, por questões internas dos países, o que acaba desmotivando as nações a contratar.

\subsection{Limites à contratação internacional}

\subsubsection{Princípio da Autonomia da Vontade e a teoria da Proper Law}

Desenvolvido nas cortes inglesas no século XIX, o princípio da autonomia da vontade teve sua aplicação fixada no momento da escolha da lei aplicável ao determinado contrato, momento em que as cortes começaram a aceitar a vontade das partes contratantes. É, em suma, a lei que as partes pretendem aplicar ao contrato em 
desenvolvimento. A intenção deve ser reconhecida pela intenção expressa no contrato, que deve ser conclusiva. Se nenhuma intenção for expressa, esta será presumida pela corte através dos termos do contrato e suas circunstâncias relevantes. Ou, ainda, determinará a proper law, que em tradução livre, compreende a "legislação mais apropriada", cujas partes teriam escolhido, quando da conclusão do contrato.

\subsubsection{Cláusula de força maior}

Nem todas as legislações concebem da mesma maneira a noção de "força maior", sendo recomendável incluir no contrato internacional a definição aplicável. No direito brasileiro, encontramos a definição no Código Civil, Parágrafo Único do artigo 393, que, de maneira sintética, define tais eventos da seguinte maneira: "o caso fortuito, ou força maior, verifica-se no fato necessário, cujos efeitos não eram possíveis evitar, ou impedir". Assim, traduzindo para o presente estudo, força maior se refere ao advento de um fato imprevisível, inevitável, exterior à vontade da parte, que torne impossível a execução da obrigação convencionada.

No entanto, a ideia central deste princípio é ligada ao fato de que, ocorrido o caso fortuito ou a força maior, deverão as partes ser exoneradas ou libertadas de sua obrigação. Esse é o efeito dos eventos previstos por essa cláusula contratual.

Embora o Código Civil Brasileiro não apresente uma distinção formal entre os institutos jurídicos do "caso fortuito" e da "força maior", limitando-se a reuní-los como causas idênticas, entre si, de exoneração de qualquer das partes e resolução absoluta da obrigação, a doutrina faz esse papel, ao apresentar os traços de distinção entre ambos. $\mathrm{O}$ caso fortuito é aquele produzido por uma força física ininteligente, enquanto a força maior decorre de fato de terceiro. Embora renomados juristas concordem que a imprevisibilidade seja uma característica, principalmente do caso fortuito, alerta ser a inevitabilidade seu ponto mais forte e também o é na força maior: tanto a seca extraordinária como o embargo da autoridade pública que impede a saída do navio do porto são fatos inevitáveis. Daí ter o Código Civil Brasileiro reunido os dois fatos na mesma definição ${ }^{3}$.

Independentemente da previsão ou da incompatibilidade dos conceitos entre os ordenamentos jurídicos, o que se faz mais necessário é estatuir o comportamento das partes dentro do determinado contrato. Das maneiras mais clássicas de criação de responsabilidades por dado preceito, usualmente temos:

3 BEVILACQUA, CLOVIS. Código Civil dos Estados Unidos do Brasil comentado. v. 4 Rio de Janeiro: F. Alves, 1955, p. 174. 
a) obrigatoriedade de notificação do evento à outra parte;

b) a forma de prova de sua ocorrência;

c) a sanção para o caso de demora ou imperfeição na notificação;

d) a exoneração da responsabilidade do devedor;

e) a suspensão da execução do contrato ou a extensão de seu termo;

f) a responsabilidade pelas despesas;

g) a obrigação de tentar contornar os efeitos da força maior originária;

h) seu término; e

i) os casos em que caberá rescisão ou renegociação quando inviável a continuidade do negócio.

No tange à renegociação, via de regra um roteiro é predeterminado no próprio bojo do contrato, a fim de que as novas condições do contrato sejam propostas.

\section{Cláusula Hardship}

Uma das técnicas utilizadas para mitigar os riscos nos contratos internacionais refere-se à aplicação de cláusulas revisionais e exoneratórias de responsabilidade, que possibilitam às partes

4 ROTTA, Mariza; FERMENTÃO, Cleide Aparecida Gomes. O Pacta Sunt Servanda - Cláusula Rebus Sic Stantibus e o Equilíbrio das Relações Contratuais na Atualidade. Disponível em: <http://periodicos. contratantes justamente reavaliar as obrigações então contraídas e suas condições de execução, ante à ocorrência de fatos que modifiquem substancialmente as conjunturas iniciais do contrato, transformando o seu equilíbrio de maneira em que o cumprimento se torne impossível ou extremamente oneroso para uma ou ambas as partes, no caso de contratos bilaterais, por exemplo ${ }^{4}$.

A cláusula hardship tem como origem as teorias revisionistas, a exemplo da cláusula rebus sic stantibus e da cláusula de onerosidade excessiva, que fomentam a ideia de que as vontades das partes não são ilimitadas, ou seja, perduram-se enquanto presente o princípio da equidade. É alternativa que possibilita ao contratante prevenirse quanto aos riscos contratuais a que está sujeito, pactuando contratos que contenham a maior quantidade possível de mecanismos de preservação da vontade manifestada, como a inclusão de cláusulas que disponham sobre as adequações necessárias no curso da execução do contrato.

Tal mecanismo, peculiar aos contratos internacionais, nasce da necessidade de manejo no que tange aos riscos adjacentes do próprio ato de contratar, que ocasionam uma série de intempéries, dificultando a adimplência dos negócios jurídicos firmados em ambiente tão

unicesumar.edu.br/index.php/revjuridica/article/vi ew/729>. Acesso em: 10.out.2015. 
particular, por vezes desprovido de regulação uniforme capaz de restaurar o equilíbrio esfacelado.

Qualquer relação contratual está sujeita ao problema do risco, seja por meio de inadimplemento involuntário ou doloso, ou ainda por razões imprevisíveis e alheias à vontade da parte de contratou. Assim sendo, a intenção da cláusula é justamente possibilitar às partes a efetiva execução da obrigação e a manutenção do equilíbrio contratual, mesmo quando o contrato se prolongar por extenso período de tempo e for submetido a eventuais e imprevisíveis fatores que cause mutação das situações fáticas.

Apesar de interessante, não se pode olvidar que a cláusula hardship é permeada de controvérsias, que se iniciam já em sua origem, prolongam-se na sua relação com o secular princípio do pacta sunt servanda e desemboca na sua estruturação prática no contrato, tornando seu estudo incontestavelmente importante e complexo. Visam, portanto, a revisão da obrigação, ou, no caso de ser esta impossível ou inviável, a rescisão do contrato. A necessidade de um instrumento que preservasse a vontade inicial das partes, não as sujeitando ao prejuízo excessivo, inesperado quando da celebração do contrato, foi prevista nos princípios do UNIDROIT - Instituo Internacional para Unificação do Direito Privado ${ }^{5}$.
Etimologicamente, traduz-se hardship como algo difícil de suportar, sofrimento, privação, adversidade. Numa definição mais exata, tem-se como hardship: uma situação em que a alteração de fatores políticos, econômicos, financeiros, legais ou mesmo tecnológicos que vigoravam na época da celebração do contrato resulte em conseqüências danosas para uma das partes. Tais modificações podem ser causadas por fenômenos geofísicos, pelas condições socioeconômicas vigentes no sistema internacional ou ainda pelas alterações no mercado internacional, advindas de crises estruturais, escassez, flutuação de preços... e suas respectivas conseqüências na política comercial, como restrições, medidas de protecionismo, dentre outras.

Orlando Gomes, em parecer transcrito por Luiz Olavo Baptista, define a cláusula hardship, como:

\footnotetext{
Uma clausula que permite a revisão do contrato se sobrevierem circunstâncias que alterem substancialmente o equilibrio primitivo das obrigações das partes. Não se trata de aplicação especial da teoria da imprevisão à qual alguns querem reconduzir a referida cláusula, (...). Trata-se de nova técnica para encontrar uma adequada reação à superveniência de fatos que alterem a economia das partes (...). Sob o controle das partes, uma série de controvérsias potenciais e para assegurar a continuação da relação em
}

\footnotetext{
${ }^{5}$ Disponível em: <http://www.unidroit.org >. Acesso em: 02.set.2015.
} 
circunstâncias que, segundo os esquemas jurídicos tradicionais, poderiam levar à resolução do contrato.

Luiz Olavo Baptista ${ }^{6}$ sublinha a semelhança entre a cláusula bardship e a cláusula de força maior no que concerne à imprevisibilidade e à inevitabilidade do evento que lhes serve como fundamento de validade, divergindo, entretanto, no grau de alteração trazido pelo evento, visto que na cláusula hardship a prestação tão somente tornase mais onerosa, enquanto na força maior torna-se impossível.

Visando pormenorizar as situações em que tal mecanismo de mitigação de risco pode ser utilizado, alguns contratos detentores da cláusula hardship procuram indicar, em seu bojo, quais são os eventos a que ela aplicar-se-ia, outros, unem este rol exemplificativo a uma fórmula genérica, e, uma terceira modalidade contratual, somente apresenta uma disposição geral, de caráter exemplificativo. De fato, não há uma forma específica de utilização da cláusula suso mencionada. Outrossim, mister se faz que a redação da premissa seja feita com grande atenção, pois os eventos variarão de acordo com o objeto do contrato.

Dentre as maiores referências globais atinentes às negociações internacionais, figura o Instituto Internacional para a Unificação do

${ }^{6}$ Dos contratos internacionais: uma visão teórica e prática. São Paulo: Saraiva, 1994.

Augusto Guzzo Revista Acadêmica, 2015, №15, 144-155
Direito Privado (UNIDROIT), que compreende uma organização intergovernamental independente, situada em Roma, cuja finalidade é justamente identificar as necessidades e os métodos de modernização, harmonização e coordenação privada do direito comercial, dos Estados e grupos de Estados, bem como, formular instrumentos uniformes de direito, princípios e regras para alcançar tais objetivos. Nesse sentido, como grande tentativa de basilar os padrões voltados aos negócios privados globais, o UNIDROIT emanou um documento intitulado "Princípios UNIDROIT Relativos aos Contratos Comerciais Internacionais", material que compila, de maneira clara e objetiva, inúmeros conceitos voltados a esses tipos contratuais.

Dentre tais definições, pode-se verificar aquela atinente à cláusula hardship, situada no Capítulo 6-que concerne ao "Adimplemento" dos contratos -, Seção 2, exclusiva para a estipulação em estudo.

O artigo 6.2.1. dos Princípios UNIDROIT é taxativo quanto ao cumprimento dos contratos internacionais, entretanto, ressalva as disposições de hardship, elencadas no artigo 6.2.2 dos Princípios do UNIDROIT ${ }^{7}$, cuja reza segue:

ARTIGO 6.2.2

(Definição de hardship)

Há hardship quando sobrevêm fatos que alteram fundamentalmente o equilibrio do contrato, seja

7 Disponível em: <http://www.unidroit.org/english/principles/contracts/ principles2010>. Acesso em: 10.out.2015.

www.fics.edu.br 152 
porque o custo do adimplemento da obrigação de uma parte tenha aumentado, seja porque o valor da contraprestação haja diminuido, e:

(a) os fatos ocorrem ou se tornam conbecidos da parte em desvantagem após a formação do contrato;

(b) os fatos não poderiam ter sido razoavelmente levados em conta pela parte em desvantagem no momento da formação do contrato;

(c) os fatos estão fora da esfera de controle da parte em desvantagem; e (d) o risco pela superveniência dos fatos não foi assumido pela parte em desvantagem.

Apesar de a tentativa de gerar uma lista taxativa dos acontecimentos albergados na cláusula hardship seja vista por muitos como algo salutar, para outros, representa um genuíno paradoxo, visto que esta cláusula se destina a registrar fatos absolutamente imprevisíveis. Em consonância ao disposto no artigo 6.2.2, alínea "a" dos Princípios UNIDROIT, é considerado obrigatório que o momento no qual a parte tome conhecimento do evento que gerou o hardship seja posterior à elaboração e conclusão do contrato, relevando o momento de ocorrência do acontecimento.

O que corrobora ainda mais com a ideia da necessidade de imprevisibilidade. E que, pautando-nos no disposto pelo artigo 6.2.1 dos Princípios UNIDROIT as partes continuam obrigadas a cumprir o contrato, ainda que a prestação se torne mais onerosa para qualquer dos polos.
Nesse âmbito, pode-se concluir que a estudada cláusula de reajuste contratual visa justamente a conservação da estabilidade dos contratos internacionais e não a terminação do ajuste.

Assim, conclui-se que, a cláusula hardship não consiste em uma exceção ao princípio do pacta sunt servanda, tal qual ocorre com a cláusula de força maior - que suscita a impossibilidade do cumprimento. Pelo contrário, a referida cláusula possibilita o efetivo cumprimento dos contratos internacionais, porque contém regras adaptadoras, que redimensionam as oscilações que perduram sobre a realidade do comércio internacional. Não há, no caso da hardship, uma rescisão do contrato, mas sim a sua revisão.

\section{Considerações Finais}

Quanto às suas características, as hardship clauses não têm estrutura pré-definida, estando as partes livres para estipularem os termos que considerarem relevantes na situação específica sobre a qual formula-se o contrato internacional. Deve-se atentar, todavia, no momento de redação desta cláusula, para diferenciação da cláusula de força maior, descrevendo os elementos que lhes dão ensejo, ainda que a imprevisibilidade seja a sua característica mais saliente.

Dentre as anotações de aconselhável uso para uma aplicação mais ajustada destas cláusulas, podemos destacar: 
(i) os principais eventos que lhe dariam ensejo;

(ii) as pessoas competentes para proceder à readaptação;

(iii) as modalidades de negociação; e

(iv) as consequências destas, ou seja, a possibilidade de intervenção de terceiros nas renegociações do contrato ou até mesmo as hipóteses de suspensão parcial ou total dos efeitos do contrato enquanto perdurar a renegociação.

Apesar de configurar como um dos elementos centrais para incidência das hardship clauses, a imprevisibilidade não é mesmo autossuficiente, sendo crucial a demonstração da extrema desvantagem gerada pelo evento superveniente.

Uma segunda conclusão, senão a principal, que se abstrai no desenvolvimento deste estudo é a configuração da cláusula hardship não como exceção frontal ao princípio do pacta sunt servanda, mas como verdadeira complementação deste. Sem quaisquer receios, pode-se afirmar que é a possibilidade de rearranjo do contrato internacional, mantendo o equilíbrio das partes, na ocorrência de eventos imprevisíveis, danosos e supervenientes, que dá a verdadeira estabilidade à força obrigatória dos contratos. Sem a possibilidade de revisão, as relações contratuais restariam visivelmente incertas e inseguras, refletindo tal fragilidade nas próprias relações do comércio internacional.

Por tudo quanto exposto, podemos asseverar que a importância da cláusula hardship diz respeito à manutenção do equilíbrio das relações contratuais, advindo da própria autonomia da vontade das partes de o readaptarem às novas realidades econômicas que se apresentem. Assim sendo, a possibilidade de uso de cláusula de tal natureza configura o ponto de equilíbrio das relações contratuais, trazendo às partes a segurança de não experimentar perdas exorbitantes geradas por fatos imprevisíveis e indesejados.

\section{Referências Bibliográficas E Eletrônicas}

ARAÚJO, Nádia de. A cláusula de hardship nos contratos internacionais e sua regulamentação nos Princípios para os contratos comerciais internacionais do UNIDROIT.

_. Contratos internacionais: novas tendências: Mercosul e Convenções Internacionais. Rio de Janeiro: Renovar, 1997. - Direito internacional privado: teoria e prática brasileira. 2ed. Rio de Janeiro: Renovar, 2004.

BAPTISTA, Luiz Olavo. Contratos Internacionais. 1 ed. São Paulo: Lex Editora, 2010. 
BASSO, Maristela. Contratos internacionais do comércio: Negociação. Conclusão. Prática. Porto Alegre: Livraria do Advogado, 1994.

. Curso de Direito Internacional Privado. 2 ed. São Paulo: Atlas, 2011.

BEVILACQUA, CLOVIS. Código Civil dos Estados Unidos do Brasil comentado. v. 4 Rio de Janeiro: F. Alves, 1955.

BORCEZZI, A. M. Responsabilidade nos contratos internacionais de compra e venda no âmbito do MERCOSUL. Unopar Cient. Ciênc. Juríd. Empres. Londrina, v. 1, n. 1, p. 111-117, mar. 2000. COSTA, José Augusto Fontoura Costa. Normas de Direito Internacional. São Paulo: Atlas, 2000. GLITZ, Frederico Eduardo Zenedin. Dissertação de Mestrado: "Uma Leitura Da Contemporaneidade Contratual: Lesão, Cláusula de Hardship e a Conservação do Contrato". Disponível em: <http://dspace.c3sl.ufpr.br/dspace/bitstream/h andle/1884/34 219/R\%20-\%20D\%20\%20FREDERICO \%20EDUARDO \%20ZENE

DIN\%20GLITZ.pdf? sequence=1>.

GOMES, Orlando. Contratos. Rio de Janeiro: Forense, 1995.

HEIN, Amanda Rosales Gonçalves. A cláusula de hardship como mecanismo de adaptação e funcionalização do contrato internacional. Disponível em: <www3.pucrs.br/pucrs/files/ uni/poa/direito/graduacao/tcc/tcc2/trabalhos2 008_1/amanda_rosales.pdf $>$.
MELO, Jairo Silva. Contratos internacionais e cláusulas hardship. São Paulo: Aduaneiras, 2000. RATTI, Bruno. Comércio internacional e câmbio. São Paulo: Aduaneiras, 1994.

RODAS, João Grandino (Coord.). Contratos internacionais. São Paulo: Editora Revista dos Tribunais, 1995.

ROTTA, Mariza; FERMENTÃO, Cleide Aparecida Gomes. O Pacta Sunt Servanda Cláusula Rebus Sic Stantibus e o Equilíbrio das Relações Contratuais na Atualidade. Disponível em:

$<$ http://periodicos.unicesumar.edu.br/index.php /revjuridica/article/view/ 729>.

SILVEIRA, Vladimir Oliveira. A Cláusula de Hardship nos Contratos de Comércio Internacional The Hardship Clause In The International Business Contracts. Disponível em: <http://www.conpedi.org.br/manaus/arquivos/ anais/XIVCongresso/077.pdf>.

STRENGER, Irineu. Contratos internacionais do comércio. São Paulo: Revista dos Tribunais, 1986. . Direito Internacional Privado. 5 ed. São Paulo: LTR, 2003.

UNIDROIT.

<http://www.unidroit.org/english/principles/co ntracts/principles2010> 